Mini Review

\title{
Recent advances of micro-algal biotechnology in Brazil
}

\section{The memory of a recent past}

In the southern part of the city of Rio de Janeiro the end of the 80 s kept what seemed to be a secret from a work of science fiction. In the simple parking of cars of the Pontifical Catholic University stood open ponds belonging to the project "Mariculture on Earth" conceived and developed by Prof. Dr. Klaus Paul Ernst Wagener, deceased in 2012. The fundamental purpose of this project was to demonstrate that a production of cyanobacteria and also of green microalgae for human consumption could be successfully performed in Brazil.

At this time the small production of the cyanobacterium Spirulina (now Arthrospira) and the microalgae Chlorella obtained on a pilot scale in the advanced laboratory of the Department of Chemistry of PUC-Rio already caused several comments in the Brazilian scientific community about a fantastic cultivation initiative in the field of applied phycology. At the beginning of the 90's the training of qualified personnel in micro-algal biotechnology - both Brazilians and foreigners was intensified. Several articles, theses and dissertations have been published.

The academic works carried out under the guidance of Professor Wagener were amplified and started to include applications as important and pioneering in Brazil as the treatment of sewage using microalgae and bacteria, the obtaining of new processes to collect biomass of microalgae, the extraction of natural dyes as phycocyanin (recently approved for human consumption in the USA) or even the construction of advanced photobioreactors capable of concentrating sunlight accelerating cell growth far beyond the limits considered conventional (Figure 1).

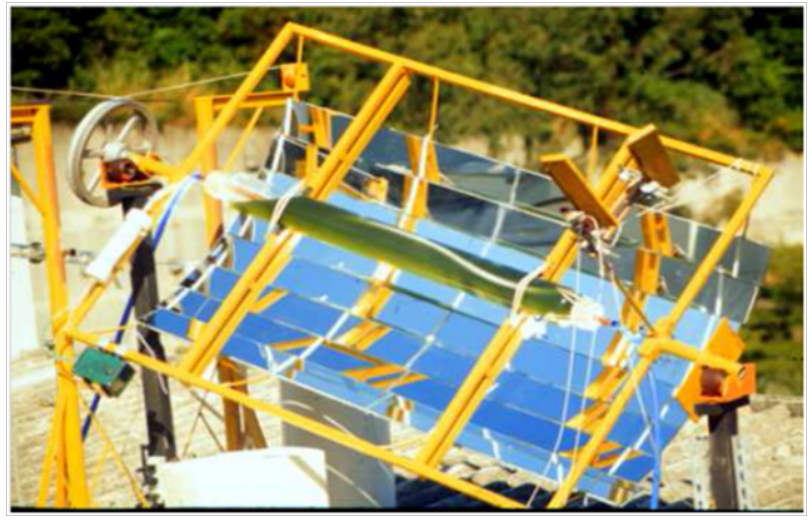

Figure I Cylindrical photobioreactor with concentrated sunlight built by author and used at the turn of the twentieth century (1999 to 200I).

There was a sense that we were somehow recovering some lost time, after several years had passed without micro-algal biotechnology being formally inserted in undergraduate and graduate courses at our universities.
Volume 5 Issue 5 - 2017

Leonardo Brantes Bacellar Mendes

Research and Development Center Leopoldo Miguez de Mello

Correspondence: Leonardo Brantes Bacellar Mendes, Research and Development Center Leopoldo Miguez de Mello, Email leobacellar@petrobras.br

Received: May 08, 2017 | Published: June 07, 2017

Meanwhile, between the 1980s and 1990s in the U.S., an extensive research program called "Aquatic Species Program" was carried out by the National Renewable Energy Laboratory (NREL) to prospect and cultivate microalgae species suitable for biodiesel production.

The fourteen-year program ended in 1994 and also included the first studies for the genetic manipulation of microalgae in order to increase their oil yield in the various cropping systems used. Throughout the program closed or open systems were used to compare results, always aiming at improving key factors such as crop stability and productivity.

Some of the conclusions drawn from NREL's efforts sounded like a kind of red alert to avoid repetitive and costly efforts, moving more quickly and safely toward scaling up the production of microalgae for biodiesel in the next decade.

In this scenario we highlight two great lessons that have been helping us achieve the much-desired scale-up for the production of microalgae fuels:

a. The use of native and wild microalgae species showed better performance than those obtained in the microalgae collections previously isolated and kept in the laboratory.

b. Increased scale demonstrated technical viability and lower costs only in open pond systems.

In this way the evolution of microalgae researches for the production of biofuels conceived at the Center of Research and Development of Petrobras (CENPES) was based on the knowledge of microalgae biotechnology developed to obtain proteins and antioxidants for human consumption.

Starting in 2005, important partnerships began to be established between Petrobras and several universities from north to south of Brazil, including the North American company MicroBio Engineering, whose CEO - Dr. John Rudiger Benemann - was elected in 2015 by the Readers of the Algae Industry Magazine as the "Algae Ambassador" (Figure 2).

In early 2006, a project called "Biodiesel from Microalgae" was started in partnership with the Federal University of Rio Grande 
(FURG) and the Federal University of Santa Catarina (UFSC), which demonstrated that it is possible to grow microalgae with high productivity in water associated with oil production (produced water).

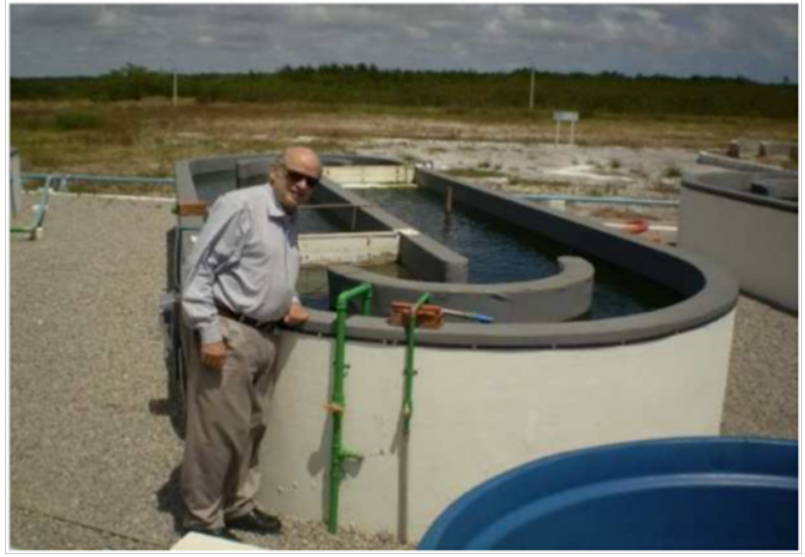

Figure 2 Dr. John R. Benemann in action on the original project of the partnership between Petrobras and UFRN in 2012.

This initial project also produced biodiesel of native microalgae from Rio Grande do Norte in laboratory scale, demonstrating the good quality of the product obtained. The excellent initial results opened the prospect for the realization of new projects designed to produce biodiesel from the oil of microalgae grown outside the laboratory environment, promoting scale up in a consistent and innovative way.

\section{Shortening the Timeline}

From then on, the first two decades of the 21st century would be marked by consistent scientific advances made with the support and initiative of Petrobras and the National Petroleum, Natural Gas and Biofuels Agency (ANP), which included - among many others:

1. Biodiesel extracted from microalgae that grow in the absence of light obtained at the State University of Campinas (Unicamp).

2. The inauguration of a pilot plant to obtain biomass with scale increase from new native species at the Aquaculture Technology Center of the Federal University of Rio (UFRN).

3. Pioneer acquisition in Brazil of a transgenic cyanobacterium strain at the Federal University of Rio Grande.

4. Extraction and conversion of microalgae oil into high quality biodiesel at the Federal University of Viçosa (UFV) and the Federal University of Rio de Janeiro (UFRJ).

Based on scientific guidance from the biotechnology sector of CENPES, in all of the above projects, valuable knowledge was acquired for the success of crop management in open systems. As a reflection of these efforts in 2015 the pilot plant built in the municipality of Extremoz (RN) produced a ton of microalgae biomass with high annual productivities (above $30 \mathrm{~g} / \mathrm{m} 2$ day) including Monoraphidium and Chlamydomonas native species from Rio Grande do Norte for the production of biodiesel (Figure 3).

At least part of the lost time was recovered, creating excellent opportunities for professionals with different backgrounds - chemists, biologists, engineers and oceanographers - to apply their skills directly to the cultivation and processing of microalgae biomass (Figure 4).

The selection and financing of new projects for the production of microalgae biomass promoted by the Ministry of Science Technology and Innovation (MCTI) was also carried out throughout this period and was fundamental for structuring large research and development projects, as well as amplifying the debate on the production of microalgae in the seminars and congresses held at national level. The biggest challenge that now arises is not to interrupt the technological evolution that has been hard won through hard and constructive work, thus avoiding moving in the direction of a time lost and very difficult to be fully recovered.

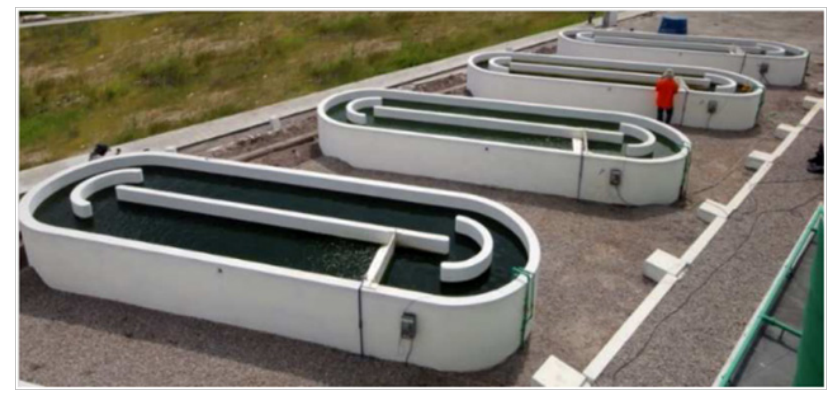

Figure 3 Pilot plant with high productivity and intense biofixation of carbon dioxide running at the Federal University of Rio Grande do Norte in 2013.

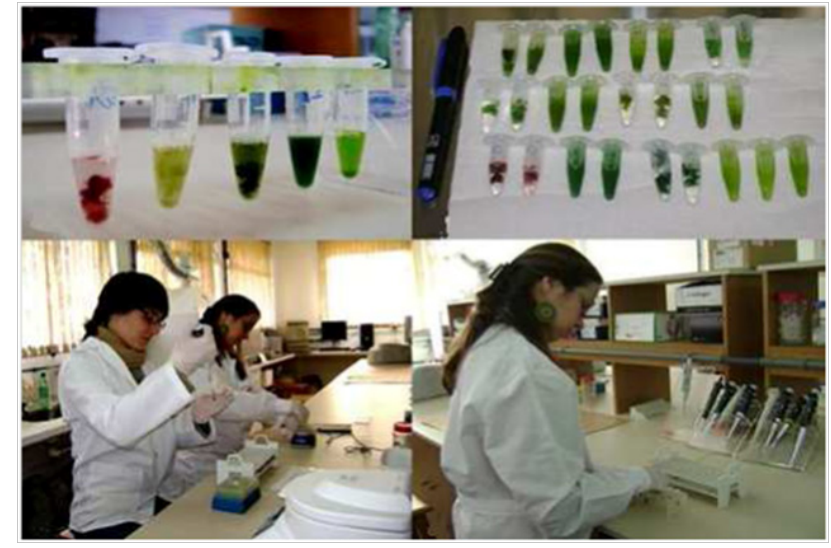

Figure 4 Production of the first transgenic cyanobacterium obtained in Brazil through the partnership between Petrobras and FURG in $201 \mathrm{I}$.

\section{Scratching the surface}

There were three decades dedicated to scientific advancement and innovation in the most diverse places of a country-continent called Brazil. A beautiful, long and laborious journey from Rio Grande do Sul to Rio Grande do Norte, passing through São Paulo, Rio de Janeiro and Minas Gerais. In this last decade the timeline has been accelerated, many creative solutions such as hydrosterification to obtain biodiesel from algal biomass have been developed by scientists and recorded through important patents that have been protecting the innovations obtained in the production of microalgae and third generation biofuels (Figure 5).

However, when it comes to cultivating, collecting and converting biomass of microalgae or cyanobacteria into products such as novel foods, antioxidants, antibiotics, or fuels, there will always exist more questions to be answered by science than answers to be promptly provided.

In fact, the international scientific community is just scratching the surface of an enormous universe of information that is yet to be revealed. New equipment for observation and collection of cells will be designed and constructed, unpublished strains will be obtained, several unknown genomes will be deciphered and many new metabolic pathways will be investigated in both microalgae and cyanobacteria. 


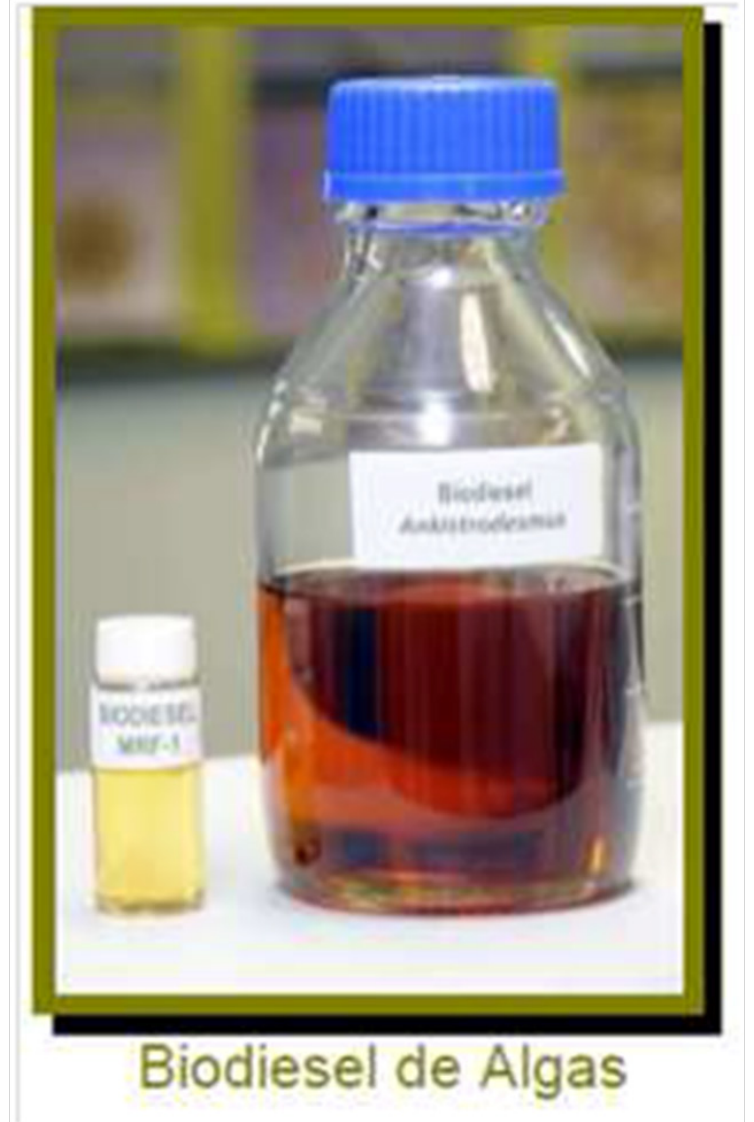

Figure 5 The first liter of microalgae Biodiesel generated through the partnership between Petrobras and UFRJ in 2012 .
It would not be too difficult to predict that microalgae production and its use in the various countries of the world will be increasing and widespread, following a trend that has been designed over the last forty years. ${ }^{1-7}$

\section{Acknowledgments}

None.

\section{Conflicts of interest}

None.

\section{References}

1. Andersen RA. Algal Culturing Techniques. Elsevier Academic Press, USA. 2005.

2. Benemann JR. Microalgae Biofuels Technology : Strain Development, Cultivation Systems, Harvesting . R\&D Needs and Recommendations, “Technology Roadmap" for Petrobras. 2013.

3. Breuer G, Lamers PP, Janssen M, et al. Opportunities to improve the areal oil productivity of microalgae. Bioresour Technol. 2015;186:294 302

4. Lundquist TJ, Woertz IC, Quinn NW, et al. A realistic technology and Engineering Assesment of Algal Biofuel Production. Cal poly. 2010.

5. Energy Bioscience Institute. University of California, Berkeley, USA. 2010

6. Mendes LB, Wagener KP. High Spirulina productivity under intensive light. Algological Studies. 2001;103:151-160.

7. Sheehan J, Dunahay T, Benemann J, et al. A Look Back at the U.S. Department of Energy's Aquatic Species Program - Biodiesel from Algae. 1998. 